\title{
INVESTIGATION OF ADIABATIC COMPRESSIBILITY AND ULTRASONIC RELAXATION IN AQUEOUS SOLUTIONS OF $N, N$-DIISOPROPYLACETAMIDE AND ZINC ACETATE
}

\author{
P. MIECZNIK
}

Institute of Acoustics, A. Mickiewicz University, Matejki 48/49, 60-769 Poznań, Poland

(Received March 14, 1994; revised version July 4, 1994; in final form August 11, 1994)

Measurements of velocity at frequency of $1 \mathrm{MHz}$ and absorption coefficient of ultrasonic waves within the range $3-50 \mathrm{MHz}$ in aqueous solutions of $N, N$-diisopropylacetamide $\left(\mathrm{D}\right.$-i-PA) and zinc acetate $\left(\left(\mathrm{CH}_{3} \mathrm{COO}\right)_{2} \mathrm{Zn}\right)$ were made. Additionally, the density of the solutions was measured. The adopted method for making the solutions helped to change the ratio of the number of non-electrolyte molecules to that of electrolyte molecules, with a constant number of water molecules. Measurements of the velocity of ultrasonic waves in the solutions under study were conducted by means of an impulse-phase interferometer. Measurements of the absorption coefficient of ultrasonic waves were conducted by means of an ultrasonic high frequency system, type Matec Instruments (USA) Model 7700. All the measurements were conducted at a constant temperature of $20^{\circ} \mathrm{C}$. On the basis of the analysis of excess functions of the molar volume and the adiabatic compressibility, the formation of solvatomers composed of $\left[(\mathrm{D}-\mathrm{i}-\mathrm{PA})_{2} \mathrm{Zn}\left(\mathrm{H}_{2} \mathrm{O}\right)_{2}\right]^{2+}$ and $\left[(\mathrm{D}-\mathrm{i}-\mathrm{PA}) \mathrm{Zn}\left(\mathrm{H}_{2} \mathrm{O}\right)_{3}\right]^{2+}$ was found. Also the complex $\left[\mathrm{Zn}\left(\mathrm{CH}_{3} \mathrm{COO}\right)_{4}\right]^{2-}$ can be recognised. The results of measurements of sound absorption indicate the occurrence of the relaxation process in the solutions under study and the frequency range used. On the basis of the relaxation theory, relaxation parameters of the process under study were calculated. The relaxation processes discovered in the system (D-i-PA)- $\mathrm{H}_{2} \mathrm{O}$ $\left(\mathrm{CH}_{3} \mathrm{COO}\right)_{2} \mathrm{Zn}$ were assigned to the formation and disintegration of solvatomers composed of $\left[(\mathrm{D}-\mathrm{i}-\mathrm{PA}) \mathrm{Zn}\left(\mathrm{H}_{2} \mathrm{O}\right)_{3}\right]^{2+}$ and probably complexes mentioned before.

PACS numbers: $43.35 .+\mathrm{d}$ 


\section{Introduction}

The investigation of adiabatic compressibility and dispersion of ultrasonic waves in solutions of electrolytes and non-electrolytes allows us to discover various facts about the physical behaviour of such solutions. As the propagation of sound waves disturbs the equilibrium between the molecules of the solvent and those of the solute, the resulting relaxation process changes the velocity of propagation and increases the absorption of sound waves.

The interactions between the ions and the molecules of the solvent in electrolyte solutions are very strong. Their energy, referred to as the energy of solvation, is almost as great as the energy of chemical bonds. Besides, the interactions are manifestly specific, i.e. the ions act selectively on relevant functional groups of the molecules of the solvent, and the direction of the interaction may be predicted in each particular case. In the case of a mixed (two-component) solvent, each ion co-ordinates around itself the functional groups of molecules of each of the two solvents - simultaneously or separately. The composition of an ion's solvation sheath in a mixed solvent does not necessarily have to be the same as in the case of the solution of an individual ingredient. In a binary mixture of solvents, each of the two solvents contributes to the solvation sheaths of both the cation and the anion. Cases of both ions being selectively dissolved by the same solvent are referred to as homoselective solvation. More interesting are cases of selective solvation of the cation by one solvent and of the anion by the other. Such processes are called heteroselective solvation. Various methods of measurement are applied in order to quantify selective solvation. One of them is ultrasonic spectroscopy.

Following numerous studies of the emergence of complexes between divalent $\mathrm{M}^{2+}$ cations and various ligands $\mathrm{L}^{z \mathcal{L}}$ in pure water solutions, the following propositions were formulated:

The process begins with hydrated ions forming outer-sphere complexes, in which ions are separated by layers of water molecules. In the next stage, whose amplitude may be slower, inner-sphere complexes appear, in which ions may neighbour with one another. Eigen and. Tamm [1] proposed the following schematic representation of the reactions

$$
\mathrm{M}_{\mathrm{aq}}^{z^{+}}+\mathrm{L}_{\mathrm{aq}}^{z_{\mathrm{L}}} \Leftrightarrow \mathrm{M}\left(\mathrm{OH}_{2}\right) \mathrm{L}^{\left(z^{+}+z_{\mathrm{L}}\right)} \Leftrightarrow \mathrm{ML}^{\left(z^{+}+z_{\mathrm{L}}\right)}+\mathrm{H}_{2} \mathrm{O} .
$$

The situation changes in the case of the solutions of electrolytes with a mixed solvent, where the water molecules in the solvation layer are replaced by the molecules of the other solvent. In such situation, in the case of an $\mathrm{M}^{z^{+}}$cation of the coordination number $k$ and the charge $z^{+}$in the mixture of two solvents $\mathrm{S}_{1}$ and $\mathrm{S}_{2}$, we might expect the emergence of inner-spherical complexes called solvatomers of the following type:

$$
\mathrm{M}\left(\mathrm{S}_{1}\right)_{i}\left(\mathrm{~S}_{2}\right)_{k-i}^{+} \quad \text { for } i=0 \div k \text {. }
$$

So far, in acoustic and volumetric studies of water solutions of electrolytes and non-electrolytes, zinc chloride was used as the electrolyte, in view of its complex-forming character [2-4]. The other solvent was $N$-methylacetamide [3] and dimethyl sulfoxide [4]. 
In the present investigation, however, a more intricate combination of substances was used, viz. a disubstituted amide, $N, N$-diisopropylacetamide (D-i-PA), as the non-electrolyte, and zinc acetate $\left[\left(\mathrm{CH}_{3} \mathrm{COO}\right)_{2} \mathrm{Zn}\right]$ as the electrolyte. Due to the use of this electrolyte, it was possible to investigate the role of the anion in the formation of mixed complexes in solutions. Because of the composition of the solutions (D-i-PA) $-\mathrm{H}_{2} \mathrm{O}-\left(\mathrm{CH}_{3} \mathrm{COO}\right)_{2} \mathrm{Zn}$, they may be considered as quasi-two-component solutions. They contain a constant amount of the molecules of water, while the ratio of the amount of electrolyte to that of non-electrolyte varies.

The ultimate aim of our ultrasonic examinations was to describe the structural changes in water solutions of $N, N$-diisopropylacetamide and zinc acetate, as well as the competitiveness of the interactions between solutions of the types $\mathrm{H}_{2} \mathrm{O}-\mathrm{D}$-i-PA and $\mathrm{H}_{2} \mathrm{O}-\left(\mathrm{CH}_{3} \mathrm{COO}\right)_{2} \mathrm{Zn}$. The measured values of the coefficient of absorption of ultrasonic waves, which changes with the wave frequency and the composition of the solutions, usually demonstrate the relaxation nature of the processes of complex formation.

\section{Method of investigation}

The velocity of propagation of ultrasonic waves in the solutions was measured with a typical pulse-phase interferometer, tuned to the frequency of $1.35 \mathrm{MHz}$ [5]. The relative error of the measurement was less than $0.1 \%$. The interferometer was made at the Institute of Acoustics of the Adam Mickiewicz University.

The density of the medium was measured with a microprocessor density meter MG-2 (made by Unilab, Poland). The method involved the measurement of the vibration period of a U-shaped tube whose vibrations were induced by a variable magnetic field [6]. The relative error of the measurement of liquid density was less than $0.001 \%$.

The coefficient of absorption of ultrasonic waves was measured with a high frequency ultrasonic measuring set US-4 (IPPT PAN, Poland), tuned to the frequency range of 30-50 MHz. For measurements in the frequency range of 3-20 $\mathrm{MHz}$, a Matec 7700 set (USA) with wide-band piezoelectric transducers was used. In both cases the transmitted impulse method was applied. The coefficient of absorption of ultrasonic waves was determined through the measurement of changes in the amplitude of the ultrasonic impulse with the changes of its transmission path in the liquid [5]. The relative error of the measurement of the coefficient of absorption of ultrasonic waves was less than $5 \%$ over the entire frequency range.

All measurements were taken at the constant temperature of $20^{\circ} \mathrm{C}$. The medium was thermostatized with the accuracy of $0.05^{\circ} \mathrm{C}$, and temperature was measured with a microprocessor temperature meter MT-1 (Unilab, Poland) connected to a piezoelectric sensor. The accuracy of the measuring set was $0.01^{\circ} \mathrm{C}$. The ratio of moles of the solute $\left\{\mathrm{D}-\mathrm{i}-\mathrm{PA}+\left(\mathrm{CH}_{3} \mathrm{COO}\right)_{2} \mathrm{Zn}\right\}$ to moles of water in the solution was $1: 50$.

The concentration of the solutions was calculated as the mole fraction of zinc acetate in the total of moles of the solute, i.e. of the sum of D-i-PA and 
$\left(\mathrm{CH}_{3} \mathrm{COO}\right)_{2} \mathrm{Zn}$, according to the following formula:

$$
x_{2}=n_{2} /\left(n_{1}+n_{2}\right) \text {, }
$$

where $x_{2}$ - the mole fraction of $\left(\mathrm{CH}_{3} \mathrm{COO}\right)_{2} \mathrm{Zn} ; n_{1}, n_{2}$ - the amount of moles of $\mathrm{D}-\mathrm{i}-\mathrm{PA}$ and zinc acetate, respectively. Thus, at $x_{2}=0$ we have a water solution of D-i-PA only, while at $x_{2}=1$ we have a solution of zinc acetate only. In the case of medium concentrations, the ratio of moles of D-i-PA and $\left(\mathrm{CH}_{3} \mathrm{COO}\right)_{2} \mathrm{Zn}$ changes, while the amount of molecules of water remains the same.

The solutions were made using the balance with the accuracy of $1 \mathrm{mg}$. In this manner the error of determination of solution's concentration $x_{2}$ was smaller than 0.0001 mole fraction.

The solutions were made from dehumidified zinc acetate $\left\{\left(\mathrm{CH}_{3} \mathrm{COO}\right)_{2} \mathrm{Zn}\right\}$ marked "pure for analysis", made by E. Merck (West Germany), $N, N$-diisopropylacetamide $\left\{\left(\mathrm{CH}_{3}\right)_{3}(\mathrm{CH})_{2} \mathrm{CON}\left(\mathrm{CH}_{3}\right)_{2}\right\}$ marked "pure $>98 \%(\mathrm{GC})$ ", made by Fluka AG (Switzerland), and twice distilled water.

\section{Results of the experiments}

\subsection{Velocity of the propagation of ultrasonic waves and density of the solutions}

The results of the measurements of the velocity of the propagation of ultrasonic waves in the solutions and of the density are presented graphically in Fig. 1. The values show the non-linearity of the ultrasound velocity as a function of composition. The same situation we can observe on the dependence of density on concentration. The differences between these quantities have resulted from the different nature of measuring features. This non-linearity will affect the function of adiabatic compressibility of the solutions.

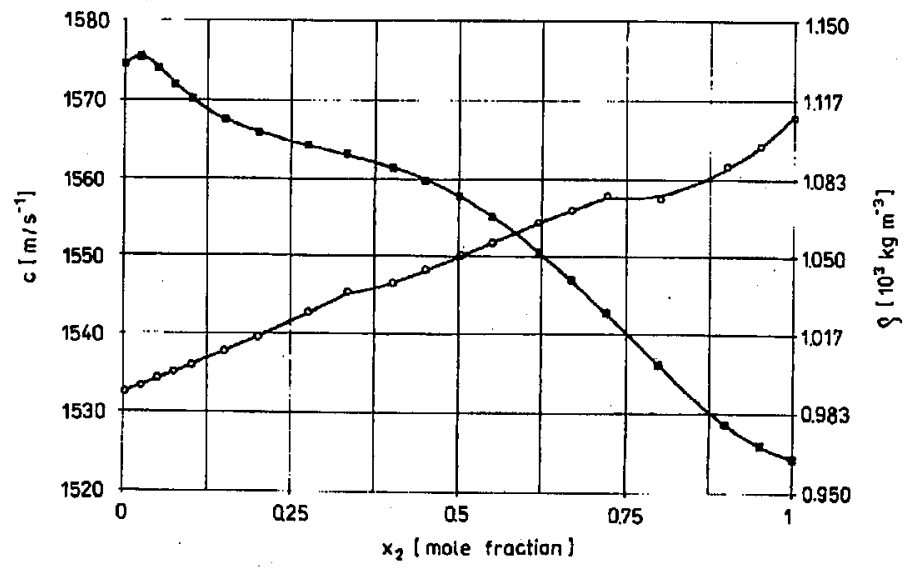

Fig. 1. Velocity of ultrasound $c$ and density $\rho$ in the solutions of D-i-PA- $\mathrm{H}_{2} \mathrm{O}-$ zinc acetate for $T=20^{\circ} \mathrm{C}$. 


\subsection{Absorption of sound waves}

Since ultrasonic relaxation may be observed in water solutions of zinc acetate [7], we should expect molecular sound absorption to take place also in a more intricate combination of substances, such as D-i-PA- $\mathrm{H}_{2} \mathrm{O}-\left(\mathrm{CH}_{3} \mathrm{COO}\right)_{2} \mathrm{Zn}$. In order to prove this supposition, the coefficient of absorption of ultrasonic waves was measured in the frequency range of $3-50 \mathrm{MHz}$, at the constant temperature $T=20^{\circ} \mathrm{C}$ and in selected solutions. Figures 2 and 3 present the results of the measurements in the form of the correlation between the value $\alpha / f^{2}(\alpha-$ the coefficient of absorption of ultrasonic waves; $f$ - wave frequency) and frequency.

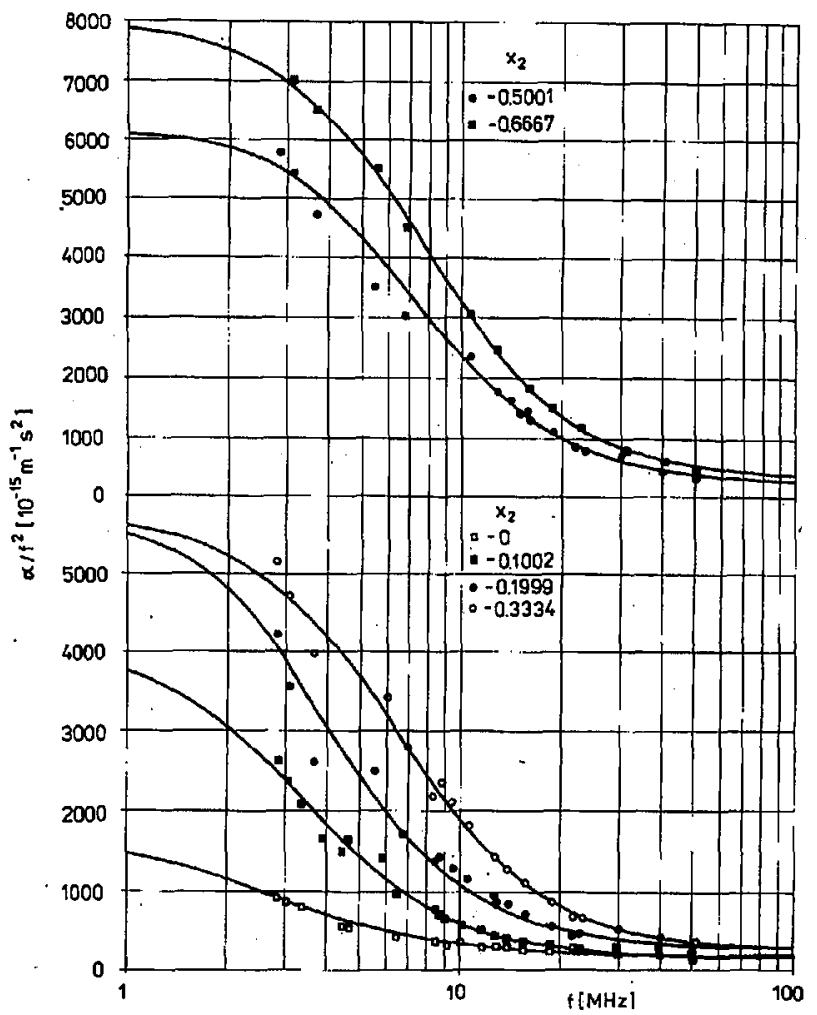

Fig. 2. Dependence of the quantity. $\alpha / f^{2}$ on frequency in the solutions D-i-PA- $\mathrm{H}_{2} \mathrm{O}$-zinc acetate for $T=20^{\circ} \mathrm{C}$.

The results show the relaxation nature of the absorption of sound waves. As it turned out, the function may be expressed with the following dependence for a single period of relaxation time [8]:

$$
\frac{\alpha}{f^{2}}=\frac{A}{\left[1+\left(f^{2} / f_{c}^{2}\right)\right]}+B
$$

where $f_{c}$ - characteristic relaxation frequency, $A$ - the constant which characterises the studied relaxation process, $B-$ the constant which accounts for the 




Fig. 3. Dependence of the quantity $\alpha / f^{2}$ on frequency in the solutions D-i-PA- $\mathrm{H}_{2} \mathrm{O}$-zinc acetate for $T=20^{\circ} \mathrm{C}$.

TABLE

Relaxatio $n$ parameters in the D-i-PA- $\mathrm{H}_{2} \mathrm{O}-\left(\mathrm{CH}_{3} \mathrm{COO}\right)_{2} \mathrm{Zn}$ system $\mathrm{T}=20^{\circ} \mathrm{C}$.

\begin{tabular}{c|c|c|c|c|c|c}
\hline \hline $\begin{array}{c}x_{2} \\
\text { [mol. frac. }]\end{array}$ & $\begin{array}{c}A \\
{\left[10^{-15} \mathrm{~m}^{-1} \mathrm{~s}^{2}\right]}\end{array}$ & $\begin{array}{c}B \\
{\left[10^{-15} \mathrm{~m}^{-1} \mathrm{~s}^{2}\right]}\end{array}$ & $\begin{array}{c}f_{\mathrm{c}} \\
{[\mathrm{MHz}]}\end{array}$ & $\begin{array}{c}\tau \\
{\left[10^{-8} \mathrm{~s}\right]}\end{array}$ & $\begin{array}{c}\mu_{\max } \\
{\left[10^{-2}\right]}\end{array}$ & $\begin{array}{c}r \\
{\left[10^{-2}\right]}\end{array}$ \\
\hline 0 & $1440 \pm 220$ & $200 \pm 10$ & $2.8 \pm 0.4$ & $5.8 \pm 0.8$ & $4.3 \pm 0.6$ & $2.7 \pm 0.4$ \\
0.1002 & $3870 \pm 370$ & $180 \pm 40$ & $3.4 \pm 0.4$ & $4.7 \pm 0.6$ & $4.6 \pm 0.5$ & $2.9 \pm 0.3$ \\
0.1999 & $5840 \pm 700$ & $300 \pm 100$ & $3.9 \pm 0.6$ & $4.2 \pm 0.6$ & $1.8 \pm 0.3$ & $1.1 \pm 0.2$ \\
0.3334 & $5490 \pm 160$ & $260 \pm 80$ & $6.5 \pm 0.3$ & $4.1 \pm 0.2$ & $3.5 \pm 0.2$ & $2.2 \pm 0.1$ \\
0.5001 & $6000 \pm 230$ & $200 \pm 130$ & $7.4 \pm 0.6$ & $2.8 \pm 0.2$ & $4: 2 \pm 0.3$ & $2.6 \pm 0.2$ \\
0.6663 & $7650 \pm 110$ & $330 \pm 60$ & $7.8 \pm 0.2$ & $2.8 \pm 0.1$ & $4.7 \pm 0.1$ & $2.9 \pm 0.1$ \\
0.7198 & $7910 \pm 580$ & $350 \pm 130$ & $7.6 \pm 0.7$ & $2.5 \pm 0.2$ & $2.7 \pm 0.2$ & $1.7 \pm 0.2$ \\
0.7998 & $7800 \pm 420$ & $340 \pm 250$ & $7.2 \pm 0.7$ & $2.2 \pm 0.2$ & $1.0 \pm 0.1$ & $0.66 \pm 0.06$ \\
0.9001 & $8990 \pm 1400$ & $700 \pm 230$ & $3.9 \pm 0.7$ & $2.2 \pm 0.4$ & $2.8 \pm 0.5$ & $1.8 \pm 0.3$ \\
0.9499 & $10176 \pm 420$ & $740 \pm 140$ & $5.4 \pm 0.4$ & $2.9 \pm 0.2$ & $3.4 \pm 0.2$ & $2.1 \pm 0.2$ \\
1 & $8110 \pm 230$ & $880 \pm 140$ & $7.3 \pm 0.4$ & $2.1 \pm 0.1$ & $4.4 \pm 0.2$ & $2.7 \pm 0.1$
\end{tabular}


so-called "classic" absorption and for other relaxation processes at higher frequencies.

Basing on the numeric presentation of the results of the measurements, the relaxation parameters - the constants $A, B$ and $f_{\mathrm{c}}$ - were calculated. Their values are presented in Table. In Figs. 2 and 3 the solid lines represent the theoretical curves plotted according to the calculated parameters $A, B$ and $f_{\mathrm{c}}$. They constitute the best fitting of the curves to the measured values.

\section{Analysis of the results}

\subsection{Excess functions of mole volume $\Delta V_{\mathrm{m}}$ and adiabatic compressibility $\Delta\left(V_{\mathrm{m}} \beta_{\mathrm{s}}\right)$}

One of the methods of determining the composition of molecular complexes developing in a solution is an investigation of the correlation between the excess functions of certain thermodynamic quantities and the composition of the solution. The excess functions chosen for the purposes of this paper were excess mole volume $\Delta V_{\mathrm{m}}$ and excess mole adiabatic compressibility $\Delta\left(V_{\mathrm{m}} \beta_{\mathrm{s}}\right)$. Since these are mole quantities, their application makes it possible to compare the properties of the solutions and to analyse the selected combinations of liquids [9].

The above-mentioned functions were calculated by means of determining the mole volume of the solutions according to the equation

$$
V_{\mathrm{m}}=\frac{\left(1-x_{2}\right) M_{1}+x_{2} M_{2}+50 M_{\mathrm{H}_{2} \mathrm{O}}}{51 \rho}
$$

where $M_{1}, M_{2}, M_{\mathrm{H}_{2} \mathrm{O}}$ - the molecular weights of D-i-PA, zinc acetate, and water, respectively; $\rho$ - the density of the solutions.

Since the solutions were made in such a way that they could be considered quasi-two-component solutions, the following correlation provided the basis for determining excess mole volume:

$$
\Delta V_{\mathrm{m}}=V_{\mathrm{m}}-\left[\left(1-x_{2}\right) V_{1}+x_{2} V_{2}\right]
$$

where $V_{1}$ - the mole volume of the solution of the concentration $x_{2}=0$ (water solution of D-i-PA); $V_{2}$ - the mole volume of the solution of the concentration $x_{2}=1$ (water solution of zinc acetate).

Basing on the known values of the mole volume $V_{\mathrm{m}}$ and the coefficient of adiabatic compressibility $\beta_{\mathrm{s}}\left(\beta_{\mathrm{s}}=1 / \rho c^{2}\right)$ of the solutions, the value of excess mole adiabatic compressibility of the solutions $V_{\mathrm{m}} \beta_{\mathrm{s}}\left(V_{\mathrm{m}} \beta_{\mathrm{s}}=-\left(\partial V_{\mathrm{m}} / \partial p\right)_{\mathrm{s}}\right)$ was determined. The excess function of adiabatic compressibility was calculated according to the equation

$$
\Delta\left(V_{\mathrm{m}} \beta_{\mathrm{s}}\right)=V_{\mathrm{m}} \beta_{\mathrm{s}}-\left[\left(1-x_{2}\right)\left(V_{\mathrm{m}} \beta_{\mathrm{s}}\right)_{1}+x_{2}\left(V_{\mathrm{m}} \beta_{\mathrm{s}}\right)_{2}\right],
$$

where $\left(V_{\mathrm{m}} \beta_{\mathrm{s}}\right)_{1}$ - adiabatic compressibility of the solution of the concentration $x_{2}=0$ (water solution of D-i-PA); $\left(V_{\mathrm{m}} \beta_{\mathrm{s}}\right)_{2}$ - adiabatic compressibility of the solution of the concentration $x_{2}=1$ (water solution of zinc acetate).

Figure 4 presents the dependence between the excess mole volume $\Delta V_{\mathrm{m}}$ and the mole fraction of zinc acetate. The shape of the curve shows a strong interaction between the components, which includes the emergence of molecular complexes. Still, the interaction is not the same throughout the range of concentration. In 
the range of the mole fraction of zinc acetate $0-0.75$ we notice negative values of $\Delta V_{\mathrm{m}}$, which proves a closer packing of molecules. The visible sharp minimum at $x_{2}=0.334$ demonstrates the emergence in the solution of this concentration of solvatomers of the composition $\left.[(\mathrm{D}-\mathrm{i}-\mathrm{PA}))_{2} \mathrm{Zn}\left(\mathrm{H}_{2} \mathrm{O}\right)_{2}\right]^{2+}$, if we assume that the coordination number of zinc is 4 . An altogether different interaction may be noticed at large concentrations of zinc acetate, i.e. in the range of $0.75<x_{2}<1$. The positive values of $\Delta V_{\mathrm{m}}$ evidence a "thinning" of the solution's structure and the emergence of constructions which are less closely packed in space. The visible maximum at $x_{2}=0.8$, i.e. at the ratio of molecules $\mathrm{D}-\mathrm{i}-\mathrm{PA}:\left(\mathrm{CH}_{3} \mathrm{COO}\right)_{2} \mathrm{Zn}$ being equal to $1: 4$, demonstrates the simultaneous presence in the solution of complex ions of the type $\left[\mathrm{Zn}\left(\mathrm{CH}_{3} \mathrm{COO}\right)_{4}\right]^{2-}$ and of solvatomers of the composition $\left[(\mathrm{D}-\mathrm{i}-\mathrm{PA}) \mathrm{Zn}\left(\mathrm{H}_{2} \mathrm{O}\right)_{3}\right]^{2+}$.

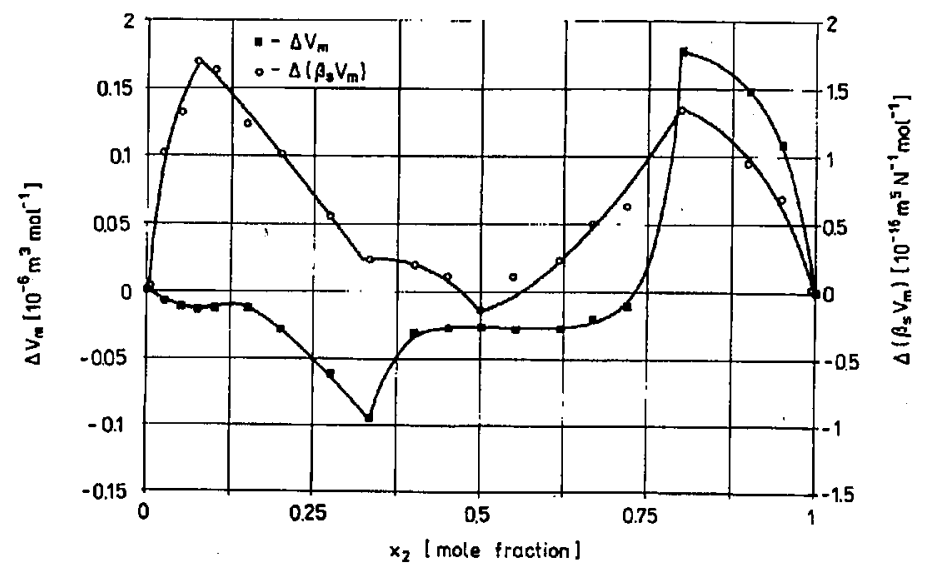

Fig. 4. Dependence of excessive molar volume $\Delta V_{\mathrm{m}}$ and excessive adiabatic compressibility $\Delta\left(V_{\mathrm{m}} \beta_{\mathrm{s}}\right)$ on concentration in the solutions $\mathrm{D}$-i-PA- $\mathrm{H}_{2} \mathrm{O}$-zinc acetate for $T=20^{\circ} \mathrm{C}$.

The correlation between excess adiabatic compressibility and concentration (Fig. 4) follows a similar pattern. Like in the case of the changes of $\Delta V_{\mathrm{m}}$, the minimum of $\Delta\left(V_{\mathrm{m}} \beta_{\mathrm{s}}\right)$ may be noticed at $x_{2}=0.334$, and the maximum - at $x_{2}=0.8$, which proves that the above-mentioned molecular complexes emerge at these ranges of concentration of the solutions. Besides, the visible additional minimum of the quantity $\Delta\left(V_{\mathrm{m}} \beta_{\mathrm{s}}\right)$ at $x_{2}=0.5$ demonstrates the presence in the solution of solvatomers of the composition $\left[(\mathrm{D}-\mathrm{i}-\mathrm{PA}) \mathrm{Zn}\left(\mathrm{H}_{2} \mathrm{O}\right)_{3}\right]^{2+}$, containing one molecule of D-i-PA per one molecule of zinc acetate. There is still another additional effect, which may be noticed in the range of small concentrations of zinc acetate $\left(0<x_{2}<0.25\right)$. The sharp maximum of excess adiabatic compressibility at $x_{2}=$ 0.075 shows that the compressibility of this solution is greater than that of initial solutions. A stoichiometric examination of the solution shows that the molecules of $\mathrm{D}-\mathrm{i}-\mathrm{PA}$ dissolve intensively the ions of zinc at the ratio of $\left(\mathrm{CH}_{3} \mathrm{COO}\right)_{2} \mathrm{Zn}: \mathrm{D}-\mathrm{i}-\mathrm{PA}$ being equal to $1: 12$, and it is probably the result of strong interactions between D-i-PA and water molecules only. 


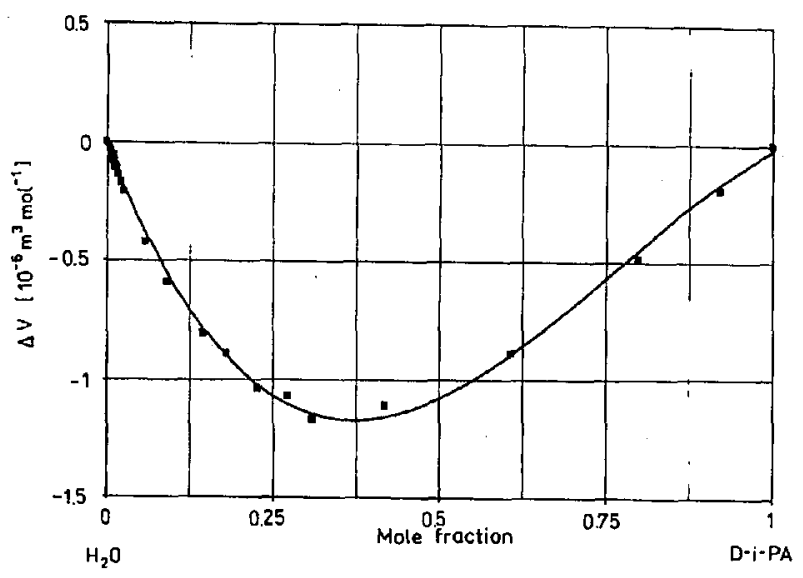

Fig. 5. Dependence of excessive molar volume $\Delta V_{\mathrm{m}}$ on concentration in the solutions $\mathrm{H}_{2} \mathrm{O}-\mathrm{D}-\mathrm{i}-\mathrm{PA}[10]$.

In the initial solutions, one should also expect intermolecular interaction causing certain structural changes. In an aqueous solution $\left(x_{2}=1\right)$, zinc acetate most probably appears in its undissociated form $\left[\mathrm{Zn}\left(\mathrm{CH}_{3} \mathrm{COO}\right)_{2}\right]$ and in its ionic form of the types $\left[\mathrm{Zn}\left(\mathrm{CH}_{3} \mathrm{COO}\right)\right]^{+}, \mathrm{Zn}^{2+}$ and $\left(\mathrm{CH}_{3} \mathrm{COO}\right)^{-}[7]$.

In order to define the interaction between water and $N, N$-diisopropylacetamide $\left(x_{2}=0\right)$, a curve illustrating the correlation between excess mole volume and concentration was plotted (Fig. 5) [10]. The minimum value of $\Delta V$ at $x_{2}=$ 0.33 proves that molecular complexes of the type 2(D-i-PA) : $\mathrm{H}_{2} \mathrm{O}$ develop in the solutions.

The mixing of the above-mentioned aqueous solutions of electrolytes and non-electrolytes produces an alteration of the initial structures and the development of new structural forms.

\subsection{Absorption of ultrasonic waves}

Basing on the values of the relaxation parameters $A, B$ and $f_{\mathrm{c}}$, and on the value of the velocity of ultrasounds for various concentrations $c$. (Fig. 1), the quantities which are characteristic of the kinetic and thermodynamic properties of the relaxation process were calculated, viz::

- the force of relaxation $r$, according to the following equation [7]:

$$
r=\frac{A c f_{\mathrm{c}}}{\pi}-\frac{1}{4}\left(1-\frac{2 B}{A}\right)\left(\frac{A c f_{\mathrm{c}}}{\pi}\right)^{2}
$$

- the time of relaxation $\tau$, according to the equation

$$
\tau=1 / 2 \pi f_{\mathrm{C}}(1-r)^{1 / 4}
$$


- the quantity $\mu_{\max }=(\alpha \lambda)_{\max }$, characteristic of the maximum absorption at the wavelength $f=f_{\mathrm{c}}$

$$
\mu_{\max }=\frac{4 \pi\left\{\left[1+r^{2} / 4(1-r)\right]^{1 / 2}-1\right\}}{r /(1-r)^{1 / 2}} .
$$

The values of these quantities are presented in Table.

The fact that the resulting characteristic frequency values of the coefficient of absorption of ultrasonic waves (Figs. 2 and 3) may be defined by dependence (3) proves that a single relaxation process occurs in the investigated solutions in the frequency range of 3-50 $\mathrm{MHz}$.

In order to ascertain the nature of the relaxation process, one must begin with determining the nature of the processes in initial solutions. It must be noted that ultrasonic dispersion takes places both at $x_{2}=1$ (Fig. 3) and at $x_{2}=0$ (Fig. 2).

Pancholy and Singal [7] suggest that in the case of a water solution of zinc acetate, the relaxation process may be accounted for by a reaction of dissociation of the type

$$
\left[\mathrm{Zn}\left(\mathrm{CH}_{3} \mathrm{COO}\right)\right]^{+} \Leftrightarrow \mathrm{Zn}^{2+}+\left(\mathrm{CH}_{3} \mathrm{COO}\right)^{-} .
$$

And yet, the complex ions (both the anion and the cation) develop gradually. Thus the reaction which involves an exchange of water molecules in the inner-spherical complexes must occur in several stages. Nevertheless, empirical observation suggests a single relaxation process. In fact, we must witness only one of several stages. As we see, it is rather difficult to account for a certain relaxation process with one reaction only.

Heed should also be paid to the fact that zinc has remarkable complex-forming properties, as well as a tetrahedral coordination ability [11]. Thus, the observed relaxation process can also be accounted for by a reaction of the development and disintegration of a complex anion of the type

$$
\left[\mathrm{Zn}\left(\mathrm{CH}_{3} \mathrm{COO}\right)_{4}\right]^{2-}+\mathrm{Zn}^{2+} \Leftrightarrow 2\left[\mathrm{Zn}\left(\mathrm{CH}_{3} \mathrm{COO}\right)_{2}\right] \text {. }
$$

The other initial solution $\left(x_{2}=0\right)$ was an aqueous solution of D-i-PA. The relaxation process which could also be noticed in this case (Fig. 2) may involve the development and disintegration of mixed complexes made from molecules of water and D-i-PA. The emergence of the complexes may be the result of an interaction through hydrogen bonds. The non-linearity of the function of excess mole volume $\Delta V$ as a function of concentration, among other factors, suggests that such complexes may actually develop (cf. Sec. 4.1.).

Let us now consider the type of relaxation processes that we should expect in the case of the investigation of three-component solutions. In view of the electrolyte's more marked impact on the characteristics of the solution, it is most likely that the most prominent reactions will be those caused by the presence of zinc acetate in the solution. Besides, zinc has remarkable complex-forming properties [11]. 
The quantities characteristic of the processes occurring in the solutions are the force of relaxation $r$ and the value of the maximum absorption of ultrasounds at a certain wavelength $\mu_{\max }$. Therefore, the concentration characteristics of these quantities may provide evidence on the nature of the processes.

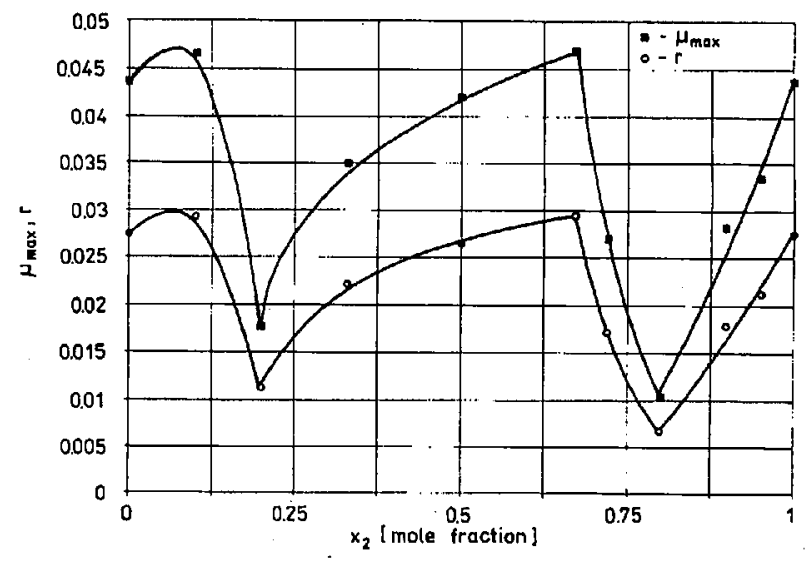

Fig. 6. Dependence of the maximal sound absorption at a specific wavelength $\mu_{\max }=$ $(\alpha \lambda)_{\max }$ and the relaxation force $r$ on concentration in the solutions $\mathrm{D}-\mathrm{i}-\mathrm{PA}-\mathrm{H}_{2} \mathrm{O}$-zinc acetate.

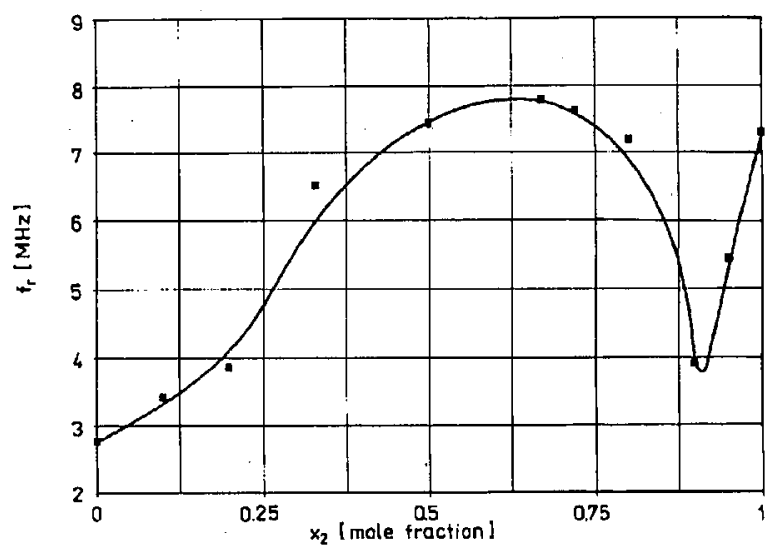

Fig. 7. Dependence of relaxation frequency $f_{c}$ on concentration in the solutions D-i-PA- $\mathrm{H}_{2} \mathrm{O}$-zinc acetate for $\mathrm{T}=20^{\circ} \mathrm{C}$.

Figure 6 demonstrates that in the case of the initial solutions $\left(x_{2}=0\right.$ and $x_{2}=1$ ), the values of $r$ and $\mu_{\max }$ are similar. On the other hand, they decrease violently in the ranges of concentration $0<x_{2}<0.2$ and $0.8<x_{2}<1$. Most probably this is a symptom of relaxation processes in the initial solutions. In these 
ranges, the force of relaxation sharply decreases, reducing the number of molecules participating in the reaction.

In the medium range of concentration, i.e. at $0.2<x_{2}<0.8$, a sudden increase in the force of relaxation and in $\mu_{\max }$ may be noticed, with the maximum at $x_{2}=0.667$, or at the ratio of molecules (D-i-PA) : $\left(\mathrm{CH}_{3} \mathrm{COO}\right)_{2} \mathrm{Zn}$ being equal to $1: 2$.

Bearing in mind the coordination number of zinc in water solutions, which is 4 , and the stoichiometric properties of the combination of substances at the maximum value of $r$ and $\mu_{\max }$, one may account for the relaxation process in this concentration range with a reaction of the type (11). Yet, if molecules of D-i-PA participate in the reaction, its formula will change somehow as

$$
\begin{gathered}
{\left[(\mathrm{D}-\mathrm{i}-\mathrm{PA}) \mathrm{Zn}\left(\mathrm{H}_{2} \mathrm{O}\right)_{3}\right]^{2+}+\left[\mathrm{Zn}\left(\mathrm{CH}_{3} \mathrm{COO}\right)_{4}\right]^{2-}} \\
\Leftrightarrow 2\left(\mathrm{CH}_{3} \mathrm{COO}\right)_{2} \mathrm{Zn}+\mathrm{D}-\mathrm{i}-\mathrm{PA}+3 \mathrm{H}_{2} \mathrm{O} .
\end{gathered}
$$

This assumption is additionally confirmed by the dependence of the relaxation frequency on concentration (Fig. 7), which also reaches its maximum at $x_{2}=0.667$. The investigation of adiabatic compressibility in the solutions proves that solvatomers of the type $\left[(\mathrm{D}-\mathrm{i}-\mathrm{PA}) \mathrm{Zn}\left(\mathrm{H}_{2} \mathrm{O}\right)_{3}\right]^{2+}$ develop (cf. Sec. 4.1).

\section{References}

[1] M. Eigen, K. Tamm, Z. Elektrochim. 66, 93 (1962).

[2] P. Miecznik, Acoustics Lett. 11, 213 (1988).

[3] P. Miecznik, J. Acoust. Soc. Am. 88, 2284 (1990).

[4] P. Miecznik, Acustica 78, 36 (1993).

[5] J. Wehr, Pomiary prędkości i ttumiena fal ultradźwiękowych, PWN, Warszawa 1972 (in Polish).

[6] J.O. Kratky, H. Leopold, H. Stabinger, Enzyme Struct. Meth. Enzymology 27D, 48 (1973).

[7] M. Pancholy, S. Singal, Nuovo Cimento 28, 292 (1963).

[8] Physical Acoustics, Ed. W.P. Mason, Vol. II, Part A, Academic Press, New York 1965.

[9] P. Miecznik, Acustica 62, 131 (1986).

[10] P. Assarsson, F.R. Eirich, J. Phys. Chem. 72, 2710 (1968).

[11] Z. Kęcki, W. Kołos, W. Libuś, S. Minc, L. Stolarczyk, Spektralne badania struktury roztworów elektrolitów, PWN, Warszawa 1969 (in Polish). 